\title{
CONCEITOS E MÉTODOS DE CONTROLE DO ESCURECIMENTO ENZIMÁTICO NO PROCESSAMENTO MÍNIMO DE FRUTAS E HORTALIÇAS
}

\author{
MARCOS VIEIRA DA SILVA* \\ CASSIA INÊS LOURENZI FRANCO ROSA** \\ EDUARDO VALÉRIO DE BARROS VILAS BOAS***
}

\begin{abstract}
Esta revisão de literatura teve como objetivo abordar o controle do escurecimento enzimático de frutas e hortaliças minimamente processadas. A ação das enzimas polifenoloxidase (PPO) e peroxidase (POD), o papel dos substratos fenólicos e as alterações nutricionais e sensoriais resultantes dessa ação foram tratados nesse artigo, bem como os métodos de controle aplicáveis ao processamento mínimo de vegetais. Os estudos revisados evidenciaram que a PPO e a POD afetam negativamente a cor dos produtos minimamente processados, e também podem reduzir o seu valor nutricional. A forma mais eficiente de controlar esse problema é a combinação entre métodos físicos e químicos por evitar o uso de tratamentos individuais mais severos, que poderiam prejudicar a aparência e a textura dos vegetais. Avanços tecnológicos na conservação póscolheita e a crescente procura por vegetais minimamente processados são determinantes para estimular a pesquisa aplicada para o controle do escurecimento enzimático, podendo resultar em menores perdas nesse segmento de mercado.
\end{abstract}

PALAVRAS-CHAVE: PROCESSAMENTO MÍNIMO; ESCURECIMENTO ENZIMÁTICO; MÉTODOS COMBINADOS.

* Tecnólogo em Alimentos, Especialista em Pós-Colheita de Frutas e Hortaliças, Universidade Tecnológica Federal do Paraná (UTFPR), Campus Campo Mourão, Campo Mourão, PR (e-mail: marcosvs@utfpr.edu.br).

** Engenheira Agrônoma, Mestre em Agronomia, Universidade Estadual de Maringá (UEM), Maringá, PR (e-mail: c_lourenzi@hotmail.com).

*** Engenheiro Agrônomo, Professor, Doutor em Ciência dos Alimentos, Universidade Federal de Lavras (UFLA), Lavras, MG (e-mail: evbvboas@ufla.br). 


\section{INTRODUÇÃO}

Frutas e hortaliças com aspecto visual indesejado, deformações geométricas, fissuras na superfície ou coloração imprópria constituem uma das fontes das perdas pós-colheita por serem rejeitadas pelo consumidor. O processamento mínimo desses vegetais é uma opção tecnológica para fornecer produtos práticos para o consumo, com segurança alimentar, e que atendam às expectativas dos consumidores quanto à qualidade em seu sentido mais amplo, e, sobretudo, aos aspectos relacionados com os atributos visuais.

A manutenção da cor nos vegetais minimamente processados representa aspecto crítico em razão da maioria deles ser susceptível ao escurecimento enzimático, causado pelas enzimas polifenoloxidase e peroxidase, que devem ser controladas sem que ocorram prejuízos sensoriais ou nutricionais aos produtos.

O objetivo deste trabalho de revisão foi apresentar estudo sobre o escurecimento enzimático que acontece na maioria dos tecidos de vegetais minimamente processados, expondo os mecanismos de ação das enzimas envolvidas e algumas vias de controle.

\section{ESCURECIMENTO DE FRUTAS E HORTALIÇAS RELACIONADO AO PROCESSAMENTO MÍNIMO}

Segundo JACOMINO et al. (2004), as frutas e hortaliças minimamente processadas são produtos frescos, higienizados, submetidos a uma ou mais alterações físicas (tais como descascamento, fatiamento e corte), tornando-os prontos para o consumo ou preparo com alterações mínimas nas propriedades sensoriais e nutricionais dos vegetais.

No processamento mínimo de frutas e hortaliças, as etapas de corte, descascamento e outras ações físicas causam injúrias e danos aos tecidos. Embora necessárias (CHITARRA, 2002), essas etapas resultam no aumento da atividade de algumas enzimas do metabolismo vegetal como, catalase, peroxidase, polifenoloxidase e fenilalanina amonia-liase. Esses sistemas enzimáticos causam o aparecimento de odores estranhos ("off flavors"), escurecimento do vegetal e lignificação da parede celular, diminuindo a qualidade do produto (HARD, 2000).

O escurecimento enzimático de vegetais inicia-se em resposta a injúrias físicas e fisiológicas (impactos, abrasões, "chilling", excesso de $\mathrm{CO}_{2}$ ) como resultado da oxidação de compostos fenólicos. As lesões provocadas durante o processamento mínimo levam ao colapso celular e à consequente descompartimentação dessas células, promovendo o contato dos compostos fenólicos com enzimas associadas ao escurecimento (PORTE e MAIA, 2001; VILAS BOAS, 2002b).

De acordo com TOMÁS-BARBERÁN e SPÍN (2001), duas enzimas são relevantes na degradação oxidativa dos compostos fenólicos por causarem a produção de polímeros de coloração marrom (melaninas): a polifenoloxidase (PPO) e a peroxidase (POD). ARAÚJO (1999) acrescentou que no tecido vegetal intacto de frutas e hortaliças também pode ocorrer escurecimento. Citou como exemplo as situações de inibição da respiração durante o armazenamento em atmosfera controlada, o uso de embalagem imprópria, a deficiência de ácido ascórbico no tecido vegetal, o armazenamento a frio e a radiação ionizante.

WHITAKER e LEE (1995) acreditam que mais de $50 \%$ das perdas em frutas ocorrem como resultado do escurecimento enzimático. MARSHALL, HIM e WEI (2000) indicaram que a alface e outros vegetais verdes folhosos, a batata e fontes de amido (como a batata-doce, fruta-pão, inhame, cogumelos e bananas), além de diversas frutas e hortaliças tropicais e subtropicais são susceptíveis ao escurecimento enzimático, causando perdas econômicas para os agricultores. O controle do escurecimento, portanto, torna-se crítico para a diminuição das perdas comerciais do agricultor e para a indústria de transformação. 


\section{POLIFENOLOXIDASE}

As polifenoloxidases (PPO) (1,2 benzenodiol: oxigênio óxido-redutase) são denominadas frequentemente de tirosinase, polifenolase, fenolase, catecol oxidase, creolase ou catecolase, dependendo dos substratos utilizados na reação de escurecimento dos tecidos vegetais. As PPO são encontradas nas plantas, nos animais e em alguns microrganismos, especialmente nos fungos, sendo glicoproteínas com massa molecular variando entre 57 a 62 kDa, à exceção da PPO do cogumelo, com valor de 128 kDa (ARAÚJO, 1999; ELBE e SCHWARTZ, 2000).

São três as reações catalisadas pela PPO na presença do oxigênio molecular: a hidroxilação de monofenóis a o-difenóis (atividade monoxigenase, E.C. 1.14.18.1), a oxidação de o-difenóis a oquinonas (atividade difenoloxidase, E.C. 1.10.3.1), e a oxidação de p-difenóis a p-quinonas (atividade lacase, E.C. 1.10.3.2) (ZAWISTOWSKI, BILIADERIS e ESKIN, 1991).

O mecanismo de ação detalhado da PPO foi descrito por BELITZ e GROSCH (1997). No centro ativo da enzima existem dois íons $\mathrm{Cu}^{+}$, cujos campos de ligação contêm dois resíduos de histidina cada um. Seguindo mecanismo ordenado, a enzima liga primeiro o oxigênio e depois o monofenol, com participação dos intermediários indicados na Figura 1. Mudança de valência dos íons cobre $\left(\mathrm{Cu}^{+} \rightarrow \mathrm{Cu}^{++}\right)$provoca a formação de complexo enzima-substrato, no qual a ligação $\mathrm{O}-\mathrm{O}$ fica tão polarizada que ocorre a hidroxilação, seguida da formação de um o-difenol. A oxidação do o-difenol a o-quinona termina o ciclo. As quinonas são compostos amarelados, instáveis e reativos que podem: reagir entre si formando polímeros com alta massa molecular de cor escura, denominados melaninas; formar complexos com aminoácidos ou proteínas; e oxidar compostos com baixo potencial de oxidoredução (NICOLAS et al., 1994).

\section{FIGURA 1 - MECANISMO GERAL DE REAÇÃO DA POLIFENOLOXIDASE}

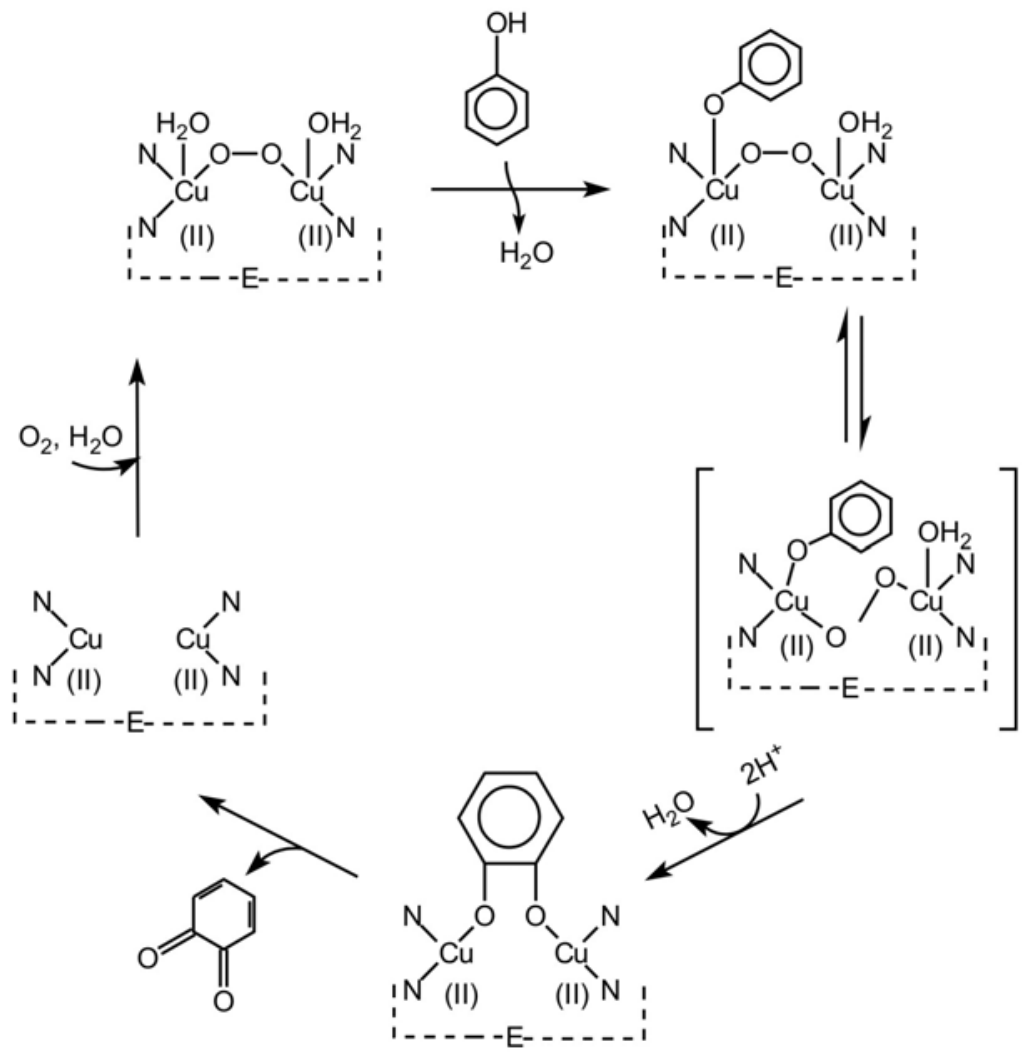

Fonte: BELITZ e GROSCH (1997). 


\section{PEROXIDASE}

Do mesmo modo que as polifenoloxidases, as peroxidases (POD) (E.C. 1.11.1.7) têm atividade típica na reação de oxidação de compostos fenólicos em presença de peróxido de hidrogênio. Também são obtidas quinonas como produto (Figura 2), as quais são instáveis e após a oxidação não enzimática na presença de $\mathrm{O}_{2}$ polimerizam-se formando as melaninas (CHITARRA, 2002).

\section{FIGURA 2 - AÇÃO DA PEROXIDASE SOBRE COMPOSTOS FENÓLICOS}

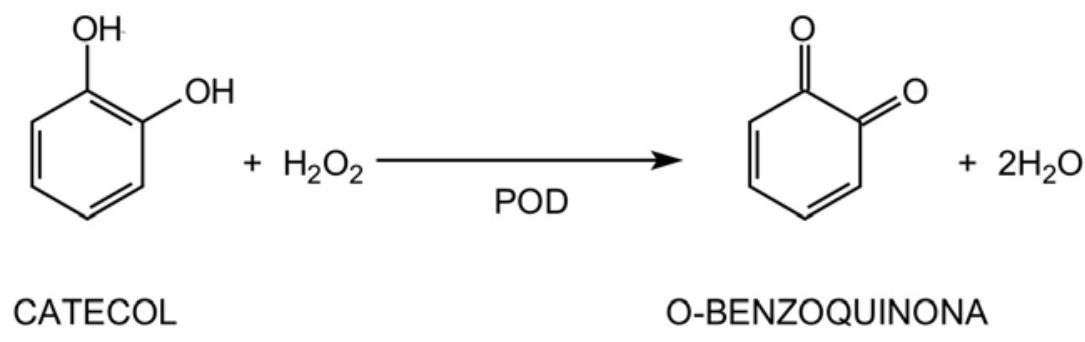

Fonte: CHITARRA (2002).

As peroxidases contêm um grupo prostético heme (ferriprotoporfirina IX) e no processo catalítico oxidam de forma transitória o íon férrico $\left(\mathrm{Fe}^{3+}\right)$ a estados de valência mais alta $\left(\mathrm{Fe}^{5+}\right.$ ou $\left.\mathrm{Fe}^{4+}\right)$. $\mathrm{O}$ peróxido $(\mathrm{ROOH})$ pode ser o de hidrogênio ou peróxido orgânico, como metil ou etil peróxido de hidrogênio. Na reação que envolve a peroxidase, o doador de elétrons pode ser o ascorbato, as aminas e outros compostos orgânicos, tais como os fenóis. O produto da oxidação apresenta em muitos casos, coloração intensa (RICHARDSON e HYSLOP, 2000).

SUBRAMANIAN et al. (1999) apontaram que a concentração interna de peróxido de hidrogênio nas plantas é pequena, o que limita a atividade da enzima. Assim, seu envolvimento é mais plausível em processos lentos como o escurecimento interno de frutas.

Além do envolvimento no processo de escurecimento enzimático, a POD também está relacionada com processos de cicatrização como, por exemplo, a lignificação (CANTOS et al., 2002).

\section{SUBSTRATOS FENÓLICOS}

Os compostos fenólicos, amplamente distribuídos no reino Plantae, são considerados como metabólitos secundários. Estruturalmente contêm um anel aromático com um ou mais grupos hidroxilas, juntamente com outros substitutos. A composição fenólica de frutas e hortaliças varia de acordo com a espécie, cultivo, grau de amadurecimento e condições ambientais de desenvolvimento e de armazenamento (MARSHALL, KIM e WEI, 2000).

O tipo e a concentração do substrato fenólico afetam diretamente o escurecimento enzimático, conforme afirmam MARTíN-BELLOSO e SOLIVA-FORTUNY (2006).

As polifenoloxidases apresentam especificidade de substrato pouco estrita. No entanto, são enzimas procedentes de distintas fontes e diferem em sua atividade relativa diante de substratos específicos. Isso explica, em parte, porque alguns vegetais escurecem mais rapidamente que outros. Alguns exemplos de substratos fenólicos e suas respectivas fontes são apresentados na Tabela 1. 


\begin{tabular}{ll}
\hline Produto & Substrato \\
\hline Banana & 3,4-diidroxifeniletilamina (dopamina) \\
\hline Maçã & Ácido clorogênico, o-catequina \\
\hline Cacau & Catequinas \\
\hline Café & Ácido clorogênico, ácido cafeico \\
\hline Berinjela & Ácido cafeico, ácido cinâmico \\
\hline Alface & Tirosina \\
\hline Cogumelo & Tirosina \\
\hline Batata & Tirosina, ácido clorogênico, flavonoides \\
\hline Chá & Flavonoides, catequinas, taninos \\
\hline Pêssego & Taninos \\
\hline Pêra & Ácido clorogênico \\
\hline
\end{tabular}

Fonte: ARAÚJO (1999).

Todas as polifenoloxidases oxidam os o-difenóis, mas algumas podem não ter atividade cresolase ou monoxigenase (não são capazes de hidroxilar monofenóis) (WONG, 1995). Os m-difenóis, como o resorcinol (Figura 3), raramente são utilizados como substratos e alguns exercem inclusive efeito inibitório (ARAÚJO, 1999).

FIGURA 3 - ESTRUTURAS QUÍMICAS DE ALGUNS SUBSTRATOS DA PPO

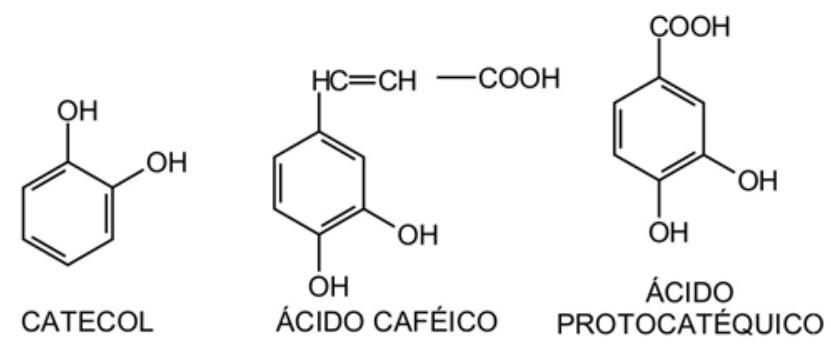

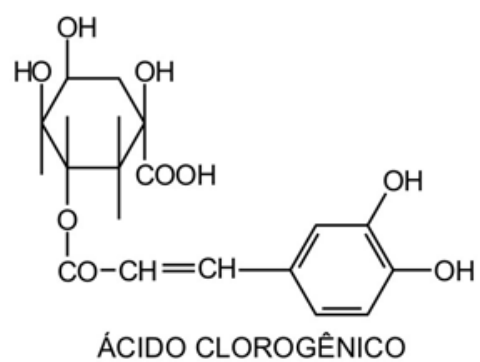<smiles>Oc1cccc(O)c1</smiles><smiles>N#COCOc1cc(O)cc(O)c1</smiles>

Fonte: ARAÚJO (1999).

\section{VALOR SENSORIAL E NUTRICIONAL DOS VEGETAIS ESCURECIDOS ENZIMATICAMENTE}

Os pigmentos escuros formados pela ação das polifenoloxidases e peroxidases são geralmente acompanhados de mudanças indesejáveis na aparência e nas propriedades sensoriais do produto, resultando na diminuição da sua vida útil e do seu valor de mercado (ARAÚJO, 1999). 
O problema do escurecimento enzimático sob o aspecto nutricional deve-se à possibilidade das o-quinonas interagirem com grupos amina e tiol, reduzindo a disponibilidade da lisina, metionina, tiamina e outros nutrientes essenciais (ARAÚJO, 1999).

A atividade da peroxidase é importante sob os pontos de vista do valor nutritivo, da cor, sabor e odor dos vegetais. A peroxidase pode promover a oxidação dos compostos fenólicos levando ao escurecimento dos tecidos vegetais. Também pode atuar na destruição oxidativa da vitamina $C$ e na descoloração das antocianinas e dos carotenoides em ausência de ácidos graxos insaturados. Além disso, pode causar a degradação peroxidativa (não enzimática) dos ácidos graxos insaturados e hidroperóxidos, produzindo radicais livres de forte aroma (RICHARDSON e HYSLOP, 2000).

Para LIMA, PASTORE e LIMA (2001), o escurecimento enzimático é benéfico para que haja a aceitação de certos alimentos como no desenvolvimento do sabor e da cor do chá preto, na diminuição do amargor e adstringência dos produtos do cacau e formação de aldeídos de aminoácidos.

\section{CONTROLE DO ESCURECIMENTO ENZIMÁTICO PARA O PROCESSAMENTO MÍNIMO}

As atividades das polifenoloxidases e das peroxidases são, na maior parte dos casos, indesejáveis em frutas e hortaliças porque a coloração parda que produzem não é agradável. Diversos métodos têm sido desenvolvidos para inibir o escurecimento enzimático, baseados na eliminação de um ou mais de seus componentes essenciais: o oxigênio, a enzima, o cobre ou o ferro do centro catalítico da PPO e da POD, respectivamente, ou o substrato, bem como as condições extrínsecas de armazenamento (LAURILA, KERVINEN e AHVENAINER, 1998).

Segundo VAMOS-VIGYAZO (1981), boa parte dos tratamentos antiescurecimento (incluindo agentes redutores, acidulantes, agentes quelantes, inibidores enzimáticos da PPO, sais inorgânicos e enzimas) são bastante investigados, mas não com intuito comercial. ARAújO (1999) reitera que poucos métodos são utilizados pela indústria de alimentos contra o escurecimento enzimático porque geralmente levam ao aparecimento de "sabor" desagradável e toxidez nos alimentos, além das questões econômicas.

\subsection{TEMPERATURA}

A refrigeração constitui o meio mais tradicional para diminuir tanto a atividade da PPO quanto da POD. As baixas temperaturas $\left(0-4^{\circ} \mathrm{C}\right)$ estão longe do ponto ótimo para essas enzimas, dificultando o acoplamento enzima-substrato pela diminuição da energia cinética das moléculas (LEE et al., 1995). Possíveis alterações na PPO ou POD (mudanças na atividade, solubilização, etc.) por meio da refrigeração dependem de fatores como o armazenamento do fruto inteiro ou fracionado, estado de amadurecimento e umidade relativa (INGHAM, PARKER e WALDRON, 1998).

O manejo da temperatura para inibir o escurecimento enzimático deve ser efetuado com muita cautela para que não ocorram problemas como as injúrias causadas pelo frio ("chilling"), ou perda de textura em tratamentos hidrotérmicos mais severos capazes de inativar os sistemas enzimáticos (HARD, 2000).

O congelamento lento dos tecidos não é indicado, pois são formados cristais de gelo capazes de romper as células vegetais. Esse fato possibilita o contato entre a PPO ou a POD com os compostos fenólicos e o oxigênio, provocando o escurecimento (embora de forma mais lenta) mesmo em baixas temperaturas (CANO, MARIN e FOSTER, 1990).

Como não se aplica tratamento térmico em vegetais minimamente processados não é possível inativar a PPO e a POD por desnaturação. Mas o estudo da atividade dessas enzimas em tomate, cenoura, berinjela (HEMEDA e KLEIN, 1991), brócolis (BARRETT et al., 2000), pimenta (RAMESH et al, 2002), e alface (MARTIN-DIANNA et al., 2005b) demonstrou que a PPO não apresenta 
termorresistência, enquanto a POD sim. Além disso, o tratamento hidrotérmico suave pode regular a síntese de compostos fenólicos ou mesmo das enzimas no período de armazenamento.

\subsection{MODIFICAÇÃO DA ATMOSFERA}

$\mathrm{Na}$ tecnologia de atmosfera modificada (AM) são usados filmes poliméricos que formam embalagens com permeabilidade diferencial para $\mathrm{O}_{2}, \mathrm{CO}_{2}, \mathrm{C}_{2} \mathrm{H}_{4}$, e vapor de água para aumentar a vida útil de vários produtos vegetais (CHITARRA e PRADO, 2002). O efeito da AM pode ser potencializado pela incorporação de atmosfera inerte com vácuo parcial ou com concentração de $\mathrm{O}_{2}$ reduzida (NICOLAS et al., 1994).

O uso de AM necessita cautela devido aos riscos dos desvios indesejáveis das vias metabólicas nos tecidos vegetais vivos causados por condições anaeróbicas (susceptibilidade à podridão, amadurecimento irregular, alterações de cor e odor). PRADO et al. (2003) observaram que a injeção de gases $\left(2 \% \mathrm{O}_{2}+10 \% \mathrm{CO}_{2}\right.$ e $\left.5 \% \mathrm{O}_{2}+5 \% \mathrm{CO}_{2}\right)$ promoveu injúria no tecido de abacaxi minimamente processado, estimulando a atividade da polifenoloxidase. Os mesmos autores indicaram a atmosfera modificada passiva como melhor tratamento para esse tipo de fruta. No entanto, o uso de atmosfera modificada ativa $\left(10 \% \mathrm{CO}_{2}, 2 \% \mathrm{O}_{2}, 88 \% \mathrm{~N}_{2}\right)$ foi mais efetivo que a atmosfera modificada passiva na conservação de batatas minimamente processadas tratadas com agentes oxidantes, mostrando índice de escurecimento 24\% menor (PINELI et al., 2005).

HINTLIAN e HOTCHKISS (1986) esclareceram que a refrigeração não deve ser suprimida no armazenamento com atmosfera modificada, devido à necessidade do controle microbiológico.

Os filmes comestíveis constituem bom complemento ao efeito benéfico do emprego da atmosfera modificada. O grau de escurecimento enzimático foi reduzido em fatias de maçãs revestidas com filme composto por proteínas do leite e carboximetilcelulose (LE TIEN et al., 2001). São efetuadas combinações com ácidos graxos, alcoóis e pectinas nos filmes comestíveis (MCHUGH e SENESI, 2000). Películas feitas a partir de polissacarídios apresentam baixa permeabilidade a gases, reduzem a respiração dos vegetais sem inibi-la (o que poderia ocasionar fermentação pela condição de anaerobiose), restringindo o acesso do oxigênio ao tecido, e por consequência, diminuindo a taxa de escurecimento enzimático (JIANG e LI, 2001).

\subsection{AGENTES QUÍMICOS}

O uso de inibidores de escurecimento enzimático em alimentos é restrito pela toxicidade que podem causar dependendo da concentração empregada, e também pelo potencial efeito negativo na textura, aroma, gosto e custos. Os inibidores químicos de escurecimento podem ser classificados de acordo com seu modo de ação primária como: agentes antioxidantes, acidulantes, quelantes ou complexantes ou inibidores enzimáticos, atuando diretamente nas enzimas, nos substratos ou ainda nos produtos de reação (MARSHAL, KIM e WEI, 2000).

Ainda não há legislação específica no Brasil para os produtos minimamente processados estabelecendo os tipos de inibidores de escurecimento permitidos e os limites de aplicação.

\subsubsection{Agentes redutores ou antioxidantes}

Conforme MARSHAL, KIM e WEI (2000), os agentes redutores atuam na prevenção do escurecimento enzimático reduzindo as o-quinonas a difenóis (sem coloração) ou reagindo irreversivelmente com elas formando produtos estáveis e sem cor.

Os sulfitos e seus derivados podem agir diretamente nas enzimas pela diminuição do número de pontes dissulfeto no centro catalítico (SAYAVEDRA-SOTO e MONTGOMERY, 1988; WALKER e FERRAR, 1998), ou nos compostos de reação, formando sulfonatos sem coloração, ou reduzindo-os aos fenóis precursores (WONG, 1995; ARAÚJO, 1999). Nesses últimos casos, a prevenção perante 
ao escurecimento é apenas temporária, uma vez que há o consumo do agente químico. O uso indiscriminado de sulfito em vegetais já foi relatado nos Estados Unidos, e relacionado com reações alérgicas e asma (SAPERS, 1993).

$O$ ácido ascórbico, ou vitamina $C$, além de atribuir valor nutricional aos alimentos, também apresenta ação redutora. Juntamente com seus sais neutros compõe um dos principais grupos de antioxidantes empregados em produtos vegetais com o intuito de prevenir o escurecimento e outras reações oxidativas de duas maneiras: (1) agindo diretamente na enzima, complexando o cobre do grupo prostético da PPO, causando sua inibição; (2) reduzindo as quinonas a sua forma anterior de fenóis, impedindo a formação dos pigmentos escuros (SAPERS e MILLER, 1998). A redução das quinonas aos seus precursores fenólicos leva à oxidação irreversível do ácido ascórbico (que é preferencialmente oxidado em relação aos compostos fenólicos) e à formação de ácido dehidro ascórbico sem atividade inibitória (MARSHALL, KIM e WEI, 2000). A eficiência do ácido ascórbico é potencializada quando combinado com outros agentes como cloreto de cálcio e cisteína (SAPERS e MILLER, 1998; REIS et al., 2004; MELO e VILAS BOAS, 2006).

O processo de inibição do escurecimento pela cisteína pode ocorrer pela sua conjugação com o-quinonas, formando compostos sem cor, ou pela redução das o-quinonas aos compostos fenólicos precursores (CILLIERS e SINGLETON, 1990). De acordo com RICHARD-FORGET, GOUPY e NICOLAS (1992), os compostos conjugados pela cisteína e o-quinonas podem agir como inibidores competitivos da PPO inclusive. No entanto, quando há quinonas em excesso e toda a cisteína foi consumida, as primeiras podem reagir com os compostos de adição cisteína-quinona, dando origem a pigmentos violetas. Quando combinada com outros agentes, como 4-hexilresorcinol ou extratos naturais de mel (VILLEGAS-OCHOA et al., 2005), cloreto de cálcio e ácido ascórbico (MELO e VILAS BOAS, 2006), a cisteína tem sua eficácia aumentada e dependendo da combinação de compostos químicos pode agir diferentemente na PPO e na POD.

\subsubsection{Agentes acidulantes}

Agentes acidulantes são geralmente utilizados para manter o $\mathrm{pH}$ do meio abaixo do ótimo para a ação catalítica das enzimas em alimentos. Exemplos de acidulantes que podem inibir o escurecimento enzimático são os ácidos cítrico, málico e fosfórico (ZEMEL et al., 1990). De acordo com RICHARDSON e HYSLOP (2000), os grupos ionizáveis da estrutura proteica das enzimas são afetados pelo $\mathrm{pH}$ do meio. Esses grupos devem permanecer na forma iônica apropriada para manter a conformação do sítio ativo da enzima, reconhecer os substratos e catalisar a reação. Mudanças no grau de ionização das enzimas são geralmente reversíveis, exceto em condições extremas de mudança de $\mathrm{pH}$, o que pode afetar também a estabilidade dos substratos.

O pH ótimo da PPO e da POD varia conforme a fonte e o substrato disponível (VAROQUAX e WILEY, 1997; LAURILA, KERVINEN e AHVENAINER, 1998; EVANGELISTA, 2001).

$O$ ácido cítrico, um dos acidulantes mais comumente usados na indústria de alimentos, pode agir como redutor do $\mathrm{pH}$ ou como quelante do cobre da enzima PPO. PASCHOALINO et al. (1993) combinaram os ácidos cítrico e ascórbico, ambos a 0,3\%, e embalagem com baixa permeabilidade de oxigênio para conservação de batatas minimamente embaladas. Tal tratamento conservou o produto sem escurecimento e com boa textura por 17 dias.

\subsubsection{Agentes quelantes}

A PPO tem um átomo de cobre no seu centro ativo e a POD um de ferro. A remoção desses metais por agentes quelantes, a exemplo dos ácidos sórbico, etileno diamino tetraacético (EDTA) e policarboxílicos (como o málico e o tartárico) causam a inativação dessas enzimas. Alguns desses também atuam como redutores de $\mathrm{pH}$ ou antioxidantes dos produtos da reação de escurecimento, como o ácido ascórbico e o cítrico (MARSHALL, KIM e WEI, 2000). 
Conforme WONG, LUH e WHITAKER (1971), o EDTA não é muito eficiente no controle do escurecimento enzimático, sendo comumente combinado com outro agente redutor e acidulante (como o ácido ascórbico e o ácido cítrico, respectivamente). Para MELO e VILAS BOAS (2006), o EDTA a $1 \%$ foi o tratamento mais efetivo em banana 'Maçã' minimamente processada contra a atividade da PPO, mas não contra a POD.

\subsubsection{Uso de sais de cálcio}

A perda da integridade da parede celular representa o início das reações de escurecimento enzimático. O corte, a queda, a ação de pectinases, hemicelulases e celulase são fatores que levam à perda da integridade da parede celular dos vegetais, e por consequência, geralmente ao início das reações de escurecimento enzimático. Soluções de sais de cálcio ajudam a manter a parede celular em bom estado: os íons de cálcio ligam-se às cadeias de pectina, formando pontes entre elas, aumentando sua força e formando pectato de cálcio (POOVAIAH, 1986; RENSBURG e ENGELBRECHT, 1986).

Bons resultados foram observados pela combinação de cloreto de cálcio com eritorbato de sódio e 4-hexilresorcinol em fatias de pêras minimamente processadas (SAPERS e MILLER, 1998). Tratamento hidrotérmico com cloreto de cálcio $1,5 \%$ a $50^{\circ} \mathrm{C} / 1 \mathrm{~min}$ em alface minimamente processada inibiu o escurecimento enzimático e reduziu a respiração do produto (MARTíN-DIANA et al., 2005a).

FAGUNDES e AYUB (2005) não constataram inibição do escurecimento enzimático em caquis inteiros da cultivar Fuyu tratados com cloreto de cálcio $2 \%$ e espalhante adesivo $0,05 \%$, devido à baixa permeabilidade da solução do sal no tecido vegetal.

\subsection{IRRADIAÇÃO}

O uso da irradiação em alimentos baseia-se na sua exposição a uma fonte de radiação ionizante suficiente para criar cargas positivas e negativas, mensurada pela unidade gray ou múltiplos (kilograys, kGy), por meio do uso de raios gama produzidos geralmente por radioisótopos de cobaldo-60 ou césio-137. Dependendo da dose de energia utilizada, os alimentos podem ser pasteurizados e até esterilizados porque o processo elimina microrganismos, exceto alguns vírus (OLSON, 1998).

Conforme POTTER e HOTCHKISS (1998), vegetais irradiados podem sofrer alterações quanto à textura e coloração. Também pode haver a formação de compostos radiolíticos, especialmente naqueles com alto conteúdo aquoso a partir da radiólise da água.

A irradiação em doses baixas (1 kGy ou menor) foi apresentada como técnica que auxilia o processamento mínimo com a finalidade de prolongar a vida útil de algumas frutas e hortaliças (LACERDA, 2000).

De acordo com BEAULIEU, D'APRANO e LACROIX (2002), a radiação gama pode afetar diretamente o escurecimento enzimático alterando a conformação estrutural proteica das enzimas, ou modificando o seu centro ativo, especificamente pela redução do íon metálico. O efeito indireto ocorre quando doses maiores de radiação alteram a permeabilidade das membranas celulares, havendo consequentemente maior entrada de oxigênio molecular no citoplasma e descompartimentação dos compostos fenólicos, provocando efeito sinérgico da oxidação desses por via enzimática e não enzimática.

Para cada vegetal existe a dose ótima de radiação, determinada principalmente pelo efeito sobre o escurecimento enzimático diante de mudanças de textura ou perda de massa fresca (LACERDA, 2000; LEITE, SILVAe SANTOS, 2003).

VILAS BOAS (2002a) comentou que deve haver maior desenvolvimento da tecnologia e redução de custos para que a irradiação de alimentos seja utilizada comercialmente. ORNELLAS et al. (2006) apontaram também que os consumidores confundem alimentos irradiados com alimentos radioativos, provocando baixa aceitação dos produtos. 
A sequência dos genes da PPO dos vegetais é bastante similar. Uma das possibilidades para diminuir a atividade da PPO e da POD, e por consequência as reações de escurecimento resultantes, é caracterizar e inativar os genes que codificam a enzima (MARSHAL, KIM e WEI, 2000).

Os genes da PPO são codificados no núcleo celular e transcritos no citoplasma. Assim, uma vez formada a pro-PPO, ela é transportada para o cloroplasto onde sofre clivagem proteolítica, gerando a forma ativa da PPO. A biologia molecular, por meio da manipulação genética, pode ser utilizada para modificar o processo de formação da PPO ativa: os RNA mensageiros tornam-se complementares, a sua tradução não ocorre e nem a formação da proteína ativa. O resultado é a produção de cultivares de frutas e de hortaliças menos propensos ao escurecimento (VAUGHN, LAX e DULE, 1988; MARTINEZ e WHITAKER, 1995).

BACHEM et al. (1994) mostraram que a inibição antisense do gene de expressão da PPO fez com que batatas transgênicas não escurecessem após o corte. Esse tipo de aplicação abre a possibilidade de prevenir o escurecimento enzimático em vários vegetais, sem o uso de tratamentos como o aquecimento ou a aplicação de antioxidantes. Com o mesmo intuito, MURATA et al. (2001) observaram que maçãs transgênicas com gene antisense de PPO apresentaram metade da intensidade de escurecimento em relação às amostras não transgênicas.

\title{
8 CONSIDERAÇÕES FINAIS
}

O escurecimento enzimático, promovido pelas polifenoloxidases e peroxidases, afeta negativamente as frutas e hortaliças minimamente processadas, tanto porque pode levar a alterações negativas no valor nutricional, como também por causar mudança indesejável de cor.

Métodos físicos e químicos são combinados para o controle do escurecimento enzimático, compondo a melhor indicação para o processamento mínimo, pois evitam o uso de tratamentos individuais mais severos que poderiam prejudicar outros atributos sensoriais dos vegetais.

Na pesquisa do escurecimento enzimático em frutas e hortaliças minimamente processadas deve-se considerar a fisiologia vegetal como um todo, já que outras enzimas que alteram a permeabilidade da membrana celular ao oxigênio, por exemplo, podem aumentar o potencial de escurecimento enzimático.

Os avanços tecnológicos na área de conservação pós-colheita, como o uso da irradiação ou do melhoramento genético, e o aumento da procura por frutas e hortaliças minimamente processadas são importantes fatores para que se invista em pesquisa aplicada na redução do escurecimento enzimático nesses produtos, haja vista a necessidade de se reduzirem as perdas decorrentes desse problema nesse segmento de mercado.

\begin{abstract}
CONCEPTS AND CONTROL METHODS OF ENZYMATIC BROWNING IN THE MINIMUM PROCESSING OF FRUITS AND VEGETABLES

This literature review aimed to address the control of enzymatic browning of minimally processed fruits and vegetables. The action of the enzymes polyphenoloxidase and peroxidase, the role of phenolic substrates, and the nutritional and sensory changes resulting from this action were treated in this article, as well as methods of control for the minimum processing of vegetables. The studies showed that the PPO and POD adversely affect the color of minimally processed products and also may reduce its nutritional value. The most efficient way to control this problem is the combination of physical and chemical methods, by avoiding the use of individual treatments more severe which could harm the appearance and texture of vegetables. Technological advances in post-harvest conservation and the growing demand for minimally processed vegetables are essential to stimulate applied research for the control of enzymatic browning which may result in lower losses in the market.
\end{abstract}




\section{REFERÊNCIAS}

1 ARAÚJO, J. M. A. Química de alimentos: teoria e prática. 2. ed. Viçosa: UFV, 1999. p. 319-329.

2 BACHEM, C.; SPECKMANN, G.; VANDERLINDE, P.; VERHEGGEN, F.; HUNT, M.; STEFFENS, J.; ZABEAU, $M$. Antisense expression of polyphenol oxidase genes inhibits enzymatic browning in potato tubers. Biol Technology, v. 12, p. 1101-1105, 1994.

3 BARRETT, D. M.; GARCIA, E. L.; RUSSELL, G. F.; RAMIREZ, E.; SHIRAZI, A. Blanch time and cultivar effects on quality of frozen and stored corn and broccoli. J. Food Sci., v. 6, n. 3, p. 534-540, 2000.

4 BEAULIEU, M.; D'APRANO, G.; LACROIX, M. Effect of dose rate of gamma irradiation on biochemical quality and browning of mushrooms Agaricus bisporus. Radiation Physics and Chemistry, v. 63, n. 3-6, p. 311-315, Mar. 2002.

5 BELITZ, H. D.; GROSCH, W. Química de los alimentos. 2. ed. Zaragoza: Acríbia, 1997. p. 119-120.

6 CANO, P.; MARIN, M. A.; FOSTER, C. Freezing of banana slices. Influence of maturity level and thermal treatment prior to freezing. J. Food Sci., v. 55, n. 4, p. 1070-1072, 1990.

7 CANTOS, E.; TUDELA, J. A.; GIL, M. I.; ESPÍN, J. C. Phenolic compounds and related enzymes are not rate-limiting in browning development of fresh-cut potatoes. J. Agric. Food Chem., v. 50, p. 3015-3023, 2002.

8 CHITARRA, A. B.; PRADO, M. E. T. Utilização de atmosfera modificada e controlada em frutos e hortaliças. Lavras: UFLA/FAEPE, 2002. p. 13-15, 23-25, 40-42.

9 CHITARRA, M. I. F. Processamento mínimo de frutos e hortaliças. Lavras: UFLA/FAEPE, 2002. p. 20, 21 , 78.

10 CILLIERS, J. J. L.; SINGLETON, V. L. Caffeic acid autooxidation and the effects of thiols. J. Agric. Food Chem., v. 38, p. 1789-1796, 1990.

11 ELBE, J. H. von; SCHWARTZ, S. J. Colorantes. In: FENNEMA, O. R. (Dir.) Química de los alimentos. Zaragoza: Acríbia, 2000. p. 587-588.

12 EVANGELISTA, J. Tecnologia de alimentos. 2. ed. São Paulo: Atheneu, 2001. p. 273, 274.

13 FAGUNDES, A. F.; AYUB, R. A. Caracterização físico-química de caquis cv. Fuyu submetidos à aplicação de agentes inibidores de escurecimento e armazenados a $0^{\circ} \mathrm{C}$. Acta Sci. Agron., v. 27, n. 3, p. 403-408, jul.-set. 2005.

14 HARD, N. F. Características de los tecidos vegetales. In: FENNEMA, O. R. (Dir.) Química de los alimentos. Zaragoza: Acríbia, 2000. p. 1005-1009.

15 HEMEDA, I. H. M.; KLEIN, B. P. Inactivation and regeneration of peroxidase activity in vegetable extracts treated with antioxidantes. J. Food Sci., v. 56, n. 1, p. 68-71, 1991.

16 HINTLIAN, C. B.; HOTCHKISS, J. H. The safety of modified atmosphere packaging: a review. Food Technol., v. 40, p. 70-76, 1986.

17 INGHAM, L. M.; PARKER, M. L.; WALDRON, K. W. Peroxidase: changes insoluble and bound forms during maturation and ripening of apples. Physiol. Plant., v. 102, p. 93-100, 1998.

18 JACOMINO, A. P.; ARRUDA, M. C. de; MOREIRA, R. C.; KLUGE, R. A. Processamento mínimo de frutas no Brasil. In: SIMPOSIUM "ESTADO ACTUAL DEL MERCADO DE FRUTOS Y VEGETALES CORTADOS EN IBEROAMÉRICA", 2004, San José. Anais... San José, Costa Rica: [s.n], 2004. p. 79-86.

19 JIANG, Y.; LI, Y. Effects of chitosan coating on postharvest life and quality of longan fruit. Food Chem., v. 73, n. 2, p. 139-143, 2001.

20 LACERDA. S. A. Radiação gama na conservação de pepinos ao natural e pré-processados, armazenados sob refrigeração. Botucatu, 2000. 84 p. Dissertação (Mestrado em Agronomia Horticultura), Universidade Estadual Paulista. 
21 LAURILA, E.; KERVINEN, R. Y.; AHVENAINER, R. The inhibition of enzymatic browning in minimally processed vegetables and fruits. Postharvest News and Information, v. 9, n. 4, p. 53-66, 1998.

22 LEE, L.; ARUL, A.; LENCKI, R.; CASTAIGNE, F. A review on modified atmosphere packaging and preservation of fresh fruits and vegetables: physiological basis and practical aspects. Packag. Tecnol. Sci., v. 8, p. 315-331, 1995.

23 LEITE, V. C.; SILVA, R. M. S.; SANTOS, A. S. Preservação de batatas e tomates por irradiação. In: ENCONTRO DE QUÍMICA DA REGIÃO SUL (SBQSUL), 11., nov., 2003, Pelotas. Anais... Santa Maria: Pallotti, 2003. p. 59.

24 LE TIEN, C.; VACHON, C.; MATEESCU, M. A.; LACROIX, M. Milk protein coatings prevent oxidative browning of apples and potatoes. J. Food Sci., v. 66, n. 4, p. 512-516, 2001.

25 LIMA, E. D. P. de A.; PASTORE, G. M.; LIMA, C. A de A. Purificação da enzima polifenoloxidase (PFO) de polpa de pinha (Annona squamosa L.) madura. Ciênc. Tecnol. Aliment., Campinas, v. 21, n. 1, p. 98-104, jan./abr. 2001.

26 MARSHALL, M. R.; KIM, J.; WEI, C. Enzymatic browning in fruits, vegetables and seafoods. Washington: FAO, 2000. Disponível em: <http://www.fao.org/ag/ags/agsi/enzymefinal/enzymatic\%20browning.htm>. Acesso em: 5 jun. 2006.

27 MARTÍN-BELLOSO, O.; SOLIVA-FORTUNY, R. Effect of modified atmosphere packaging on the quality of fresh-cut fruits. Stewart Postharvest, v. 2, n. 1, fev. 2006. Disponível em: <http:// www.stewartpostharvest.com>. Acesso em: 02 jun. 2006.

28 MARTIN-DIANA, A. B.; RICO, D.; BARRY-RYAN, C.; MULCAHY, J.; FRIAS, J.; HENEHAN, G. T. M. Calcium lactate washing treatments for salad-cut iceberb lettuce: effect of temperature and concentracion on quality retention parameters. Food Res. Int., v. 38, n. 7, p. 729-740, 2005a.

29 . Effect of heat shock on browning-related enzymes in minimally processed iceberg lettuce and crude extracts. Biosci. Biotechnol. Biochem., v. 69, n. 9, p. 1677-1685, 2005b.

30 MARTINEZ, M. V.; WHITAKER, J. R. The biochemistry and control of enzymatic browning. Trends Food Sci. Technol., v. 6, p. 195-200, 1995.

$31 \mathrm{MCHUGH}, \mathrm{T}$. H.; SENESI, E. Apple wraps: a novel method to improve the quality and extend the shelf-life of fresh-cut apples. J. Food Sci., v. 65, n. 3, p. 480-485, 2000.

32 MELO, A. A. M.; VILAS BOAS, E. V. B. Inibição do escurecimento enzimático de banana maçã minimamente processada. Ciênc. Tecnol. Aliment., v. 26, n. 1, p. 110-115, jan./mar. 2006.

33 MURATA, M.; NISHIMURA, M.; MURAI, N.; HARUTA, M.; HOMMA, S.; ITOH, Y. A transgenic apple callus showing reduced polyphenol oxidase activity and lower browning potential. Biosci. Biotechnol. Biochem., v. 65, n. 2 , p. 383-388, 2001.

34 NICOLAS, J. J.; RICHARD-FORGET, F. C.; GOUPY, P. M.; AMIOT, M. J.; AUBERT, S. Y. Enzymatic browning reaction in apple and apple products. Crit. Rev. Food Sci. Nutr., v. 34, p. 109-157, 1994.

35 OLSON, D. G. Irradiation of food. Food Techonol., v. 52, n. 1, p. 56-62, jan. 1998.

36 ORNELLAS, C. B. D.; GONÇALVES, M. P. J.; SILVA, P. R.; MARTINS, R. T. Atitude do consumidor frente à irradiação de alimentos. Ciênc. Tecnol. Aliment., Campinas, v. 26, n. 1, p. 211-213, jan./mar. 2006.

37 PASCHOALINO, J. E.; NISIDA, A. L. A. C.; GARCIA, E. E. C.; TOCCHINI, R. P. Prevenção do escurecimento em batatas frescas descascadas e fatiadas. Colet. Inst. Tecnol. Alimentos, v. 2, n. 23, p. 189-197, jul./ dez. 1993.

38 PINELI, L. L. O.; MORETTI, C. L.; ALMEIDA, G. C.; NASCIMENTO, B. G.; ONUKI, A. C. A. Associação de atmosfera modificada e antioxidantes reduz o escurecimento de batatas "Ágata" minimamente processadas. Hort. Bras., Brasília, v. 23, n. 4, p. 993-997, out./dez. 2005.

39 PORTE, A.; MAIA, L. H. Alterações fisiológicas, bioquímicas e microbiológicas de alimentos minimamente processados. B. CEPPA, Curitiba, v. 19, n. 1, p. 105-118, jan./jun. 2001. 
40 POTTER, N. N.; HOTCHKISS, J. H. Food science. $5^{\text {th }}$ ed. Aspen: Gaithersburg, 1998. p. 249, 250.

41 POOVAIAH, B. W. Role of calcium in prolonging storage life of fruits and vegetables. Food Technol., v. 40, p. 86-89, 1986.

42 PRADO, M.E.T.; CHITARRA, A.B.; BONNAS, D.S.; PINHEIRO, A.C.M.; MATTOS L.M. Armazenamento de abacaxi 'Smooth Cayenne' minimamente processado sob refrigeração e atmosfera modificada. Rev. Bras. de Frut., v. 25, n. 1, p. 67-70, 2003.

43 RAMESH, M. N.; WOLF, W.; TEVINI, D.; BOGNÁR, A. Microwave blanching of vegetables. J. Food Sci., v. 67, n. 1, p. 390-398, 2002.

44 REIS, C. M. F.; VILAS BOAS, E. V. B.; BOARI, C. A.; PÍCCOLI, R. H. Qualidade e vida de prateleira de banana prata minimamente processada. Ciên. e Agrotec., v. 28, n. 3, p. 702-708, 2004.

45 RENSBURG, E. van; ENGELBRECHT, A. H. P. Effect of calcium salts on susceptibility to browning of avocado fruit. J. Food Sci., v. 51, n. 4, p. 1067-1068, 1986.

46 RICHARD-FORGET, F. M.; GOUPY, P. M.; NICOLAS, J. J. Cysteine as an inhibidor of enzymatic browning. II. Kinetc studies. J. Agric. Food Chem., v. 40, p. 2108-2113, 1992.

47 RICHARDSON, T.; HYSLOP, D. B. Enzimas. In: FENNEMA, O. R. (Dir.) Química de los alimentos. Zaragoza: Acríbia, 2000. p. 501-503.

48 SAPERS, G. M. Browning of foods: control by sulfites, antioxidants and other means. Food Tech., v. 47, p. 75-84, 1993.

49 SAPERS, G. M.; MILLER, R. L. Browning inhibition in fresh-cut pears. J. Food Sci., v. 63, n. 2, p. 342-346, 1998.

50 SAYAVEDRA-SOTO, L. A.; MONTGOMERY, M. W. Response contour diagrams to describe effects of moisture, storage, temperature, and sulfur dioxide on color of dried apples. J. Food Sci., v. 53, n. 2, p. 643644, 1988.

51 SUBRAMANIAN, N.; VENKATESH, P.; GANGULI, S.; SINKAR, V. P. Role of polyphenol oxidase and peroxidase in the generation of blach tea theaflavins. J. Agric. Food Chem., n. 47, p. 2571-2578, 1999.

52 TOMÁS-BARBERÁN, F. A.; ESPÍN, J. C. Phenolic compounds and related enzymes as determinants of quality in fruits and vegetables. J. Sci Food Agri., n. 81, p. 853-879, mar. 2001. Disponível em: <http:// www.interscience.wiley. com>. Acesso em: 04 jun. 2006.

53 VAMOS-VIGYAZO, L. Polyphenol oxidase and peroxidase in fruits and vegetables. Crit. Rev. Food Sci. Nutr., v. 15, p. 49-127, 1981.

54 VAROUQUAUX, P.; WILEY, R. C. Cambios biológicos y bioquímicos en frutas y hortalizas refrigeradas minimamente processadas. In: WILEY, R. C. (Org.). Frutas y hortalizas minimamente procesadas y refrigeradas. Zaragoza: Acríbia, 1997. p. 242.

55 VAUGHN, K. C.; LAX, A. R.; DUKE, S. O. Polyphenol oxidase: the chloroplast oxidase with no established function. Physiol. Plant., v. 72, p. 659-665, 1988.

56 VILAS BOAS, E. V. B. Perdas pós-colheita. Lavras: UFLA/FAEPE, 2002a. p. 53.

57 VILAS BOAS, E. V. B. Qualidade de alimentos vegetais. Lavras: UFLA/FAEPE, 2002b. p. 59.

58 VILLEGAS-OCHOA, M.; AYALA-ZAVALA, J. F.; VALENZUELA, R. C.; HERNÁNDEZ, J.; GONZÁLEZ-AGUILAR, G. A. Efecto antioxidante de extractos naturales en manzana 'Red Delicious'. In: SIMPOSIUM "ESTADO ACTUAL DEL MERCADO DE FRUTOS Y VEGETALES CORTADOS EN IBEROAMÉRICA”, 2005, La Habana. Anais... La Habana, Cuba: [s.n], 2005. p. 25-32.

59 WALKER, J. R. L.; FERRAR, P. H. Diphenol oxidases, enzyme-catalysed browning and plant disease resistance. Biotech. Gen. Eng. Rev., v. 15, p. 468, 1998.

60 WHITAKER, J. R.; LEE, C. Y. Recent advances in chemistry of enzymatic browning. In: Enzymatic browning and its prevention. Washington: American Chemical Society, 1995. p. 2-7. 
61 WONG, D. W. S. Química de los alimentos: mecanismos e teoria. Zaragoza: Acríbia, 1995. p. 233-236, $365,372$.

62 WONG, T. C.; LUH, B. S.; WHITAKER, J. R. Isolation and characterization of polyphenol oxidase isozymes of clingstone peach. Plant Physiol., n. 48, p. 19-23, 1971.

63 ZAWISTOWSKI, J.; BILIADERIS, C. G.; ESKIN, N. A. M. Poliphenol oxidase. In: ROBINSON, D. S.; ESKIN, N. A. M. (Ed.) Oxidative enzymes in foods. London: Elsevier Science, 1991. p. 218-220.

64 ZEMEL G. P.; SIMS, C. A.; MARSHALL, M. R.; BALABAN, M. Low pH inactivation of polyphenoloxidase in apple juice. J. Food Sci., v. 55, p. 562-563, 1990. 